\title{
Kinerja Guru Penjas SD di Masa Pandemi Covid-19: Pengaruh Praktek MSDM Terhadap Kinerja Guru Penjas SD
}

\author{
Immanuel Muammal', Abdurrohman Muzakki² \\ 1 Universitas Muhammadiyah Malang, Malang, Indonesia \\ 2 Universitas Muhammadiyah Malang, Malang, Indonesia \\ *Corresponding author: immanuelmuammal@umm.ac.id
}

\begin{abstract}
This study aims to analyze the effect of the practice of Human Resource Management (MSDM) applied by schools on the performance of Elementary School Physical Education Teachers. This type of research is an explanatory study with a quantitative approach. The variables in this study include the practice of HRM and the performance of Elementary School Physical Education teachers. This study reached 102 Physical Education teachers at the elementary school level in the Malang Raya area. Data obtained from distributing questionnaires both physically and online. Data analysis was performed using SEM-PLS with WARP PLS 7 software. The results of this study indicate that during the Covid-19 pandemic, HRM practice has no influence on the performance of Elementary School Physical Education Teachers with a significance value of 0.30 .
\end{abstract}

Keywords: msdm practices; primary school physical education teacher performance; school management

\begin{abstract}
ABSTRAK
Penelitian ini bertujuan untuk menganalisis pengaruh praktek Manajemen Sumber Daya Manusia (MSDM) yang diterapkan sekolah terhadap kinerja Guru Penjas SD. Jenis penelitian ini adalah penelitian explanatory dengan pendekatan kuantitatf. Variabel dalam penelitian ini meliputi praktek MSDM dan kinerja Guru Penjas SD. Penelitian ini menjangkau 102 guru pendidikan jasmani olahraga dan kesehatan di tingkat sekolah dasar yang berada di wilayah Malang Raya. Data diperoleh dari penyebaran kuesioner yang diperoleh dengan sistem secara offline dan juga secara online. Analisis data dilakukan menggunakan SEM-PLS dengan software WARP PLS 7. Hasil dari penelitian ini mengindikasikan bahwa selama pandemi covid-19, Praktek MSDM tidak memiliki pengaruh terhadap kinerja Guru Penjas SD dengan nilai signifikansi 0.30.

Kata Kunci: kinerja guru penjas sd; manajemen sekolah; praktek msdm
\end{abstract}

\section{Pendahuluan}

Pandemi Covid-19 membuat pemerintah menginstruksikan sekolah untuk menghentikan pembelajaran tatap muka dan menggantinya dengan pembelajaran online (Daniel,2020). Pandemi juga memaksa banyak negara menerapkan kebijakan lockdown yang berdampak pada dihentikannya banyak kegiatan olahraga (Wong et al,2020). Kegiatan pembelajaran olahraga sekolah yang biasanya dilakukan diluar ruangan, maka ketika pandemi pembelajaran dilakukan secara online. Hal ini menuntut guru untuk menyesuaikan diri agar pembelajaran tetap dapat dilaksanakan dengan baik. Selain itu kondisi seperti pandemi ini menjadi tantangan bagi guru olahraga untuk memberiktivitasnya agar proses pembelajaran tetap berjalan. Dalam keadaan pandemi seperti sekarang ini guru olahraga harus memahami bahwa pembelajaran tidak mungkin dilakukan dengan cara tradisional.

Keberhasilan dunia pendidikan dipengaruhi oleh berbagai faktor seperti guru, fasilitas serta prasarana, dan area belajar yang efisien dan kondusif. Sumber daya manusia dalam dunia pendidikan yaitu guru, memiliki peran sangat berarti dalam keberhasilan pendidikan di sekolah sebab seseorang guru yang menolong pertumbuhan siswa. Hal ini menunjukkan bahwa pendidikan benar-benar merupakan pelopor dan pertanda pembangunan nasional. 
Memang, ditegaskan bahwa pendidikan adalah proses yang memfasilitasi, pembelajaran dan perolehan keterampilan teoritis dan praktis bagi orang-orang untuk memanfaatkan lingkungan secara efektif untuk pertumbuhan dan perkembangan masyarakat atau bangsa mana pun. Menurut Akpakwu (2012) pendidikan adalah proses membawa perubahan yang diinginkan ke dalam perilaku sebagai manusia. Dengan demikian, perubahan dan sikap individu yang diinginkan sebagai produk sampingan dari pengetahuan dan keterampilan yang diperoleh menjadikan mereka anggota masyarakat yang berguna dan dapat diterima, serta berkontribusi pada pertumbuhan dan perkembangan masyarakat.

Faktor yang mempengaruhi kinerja adalah praktek manajemen sumber daya manusia (MSDM) dari sekolah. Kinerja sekolah akan meningkat dengan intensitas MSDM. Praktek MSDM juga memainkan peran penting di sektor non-profit seperti sekolah. Penelitan menunjukkan jika praktik MSDM berkorelasi dengan peningkatan kinerja sekolah, termasuk guru di dalamnya (Bryson et al, 2018). Sistem manajemen sumber daya (MSDM) harus berisi sekumpulan kebijakan dan praktik yang saling terkait yang secara eksplisit ditargetkan untuk menarik, mempertahankan, mengembangkan dan memberi penghargaan kepada guru sedemikian rupa sehingga menghasilkan kinerja guru dan sekolah yang optimal (Runhaar and Runhaar, 2012). Menurut teori pertukaran sosial, yang dikembangkan oleh Whitener, Zacharatos, et al., (2005) praktik manajemen sumber daya (MSDM) yang dianggap oleh karyawan untuk menunjukkan komitmen organisasi kepada staf atau bawahan akan mempunyai timbal balik dengan sikap dan perilaku positif apabila manajemen sumber daya (MSDM) tersebut sesuai dengan tujuan dari visi dan misi yang sudah ditentukan.

Evaluasi kinerja adalah salah satu proses terpenting yang diperlukan untuk mengukur efektivitas organisasi. Evaluasi kinerja adalah alat yang direncanakan dengan baik yang memeriksa dan mengintegrasikan keberhasilan, sikap, dan perilaku individu di tempat kerja secara rinci dan yang menilai kontribusi individu terhadap keberhasilan organisasi. Evaluasi kinerja menjadi penentu apakah manajemen sumber daya (MSDM) berjalan dengan semestinya yang sudah ditentukan dari awal. Banyaknya pemahaman yang kurang terhadap evaluasi kinerja dikarenakan sistem manajemen sumber daya (MSDM) yang buruk atau tidak tersistem. Kunci keberhasilan evaluasi kinerja sendiri bergantung pada manajemen sumber daya (MSDM) yang menjadi landasan untuk bekerja. Sehingga manajemen sumber daya (MSDM) menjadi kekuatan untuk mengolah sistem dan bahan kajian bagi suatu organisasi.

Pendidikan memegang peranan penting dalam membentuk masyarakat dan pembangunan bangsa. Guru dipandang sebagai alat bantu penglihatan dan pendengaran yang ada dalam setiap kegiatan pembelajaran yang akan mengukir ingatan emosi siswa. Seorang guru yang unggul akan berhasil menyederhanakan pengajarannya agar mudah dipahami oleh siswa (Hamidi, 2007). Menurut Geringer (2010), guru yang baik dan berkualitas merupakan salah satu faktor yang mempengaruhi pembelajaran siswa dibandingkan dengan faktor lain seperti ukuran kelas dan keuangan. Oleh karena itu, guru harus membekali diri dengan pengetahuan dan keterampilan khusus untuk menyelesaikan tugas dan tanggung jawabnya di kelas. Itu menjadi penting karena tantangan dan kompleksitas pengajaran. Masalah tersebut dapat diatasi jika guru memiliki kompetensi yang tinggi dan memenuhi standar sebagai guru.

Pertama, kinerja sekolah akan meningkat dengan intensitas manajemen sumber daya (MSDM). Kedua, beberapa praktik MSDM dianggap berharga di sektor nirlaba mungkin juga bermanfaat di sekolah, yang lain mungkin kurang berguna di sekolah. Kami menemukan 
penggunaan intensif praktik manajemen sumber daya (MSDM) berkorelasi dengan peningkatan substansial dalam kinerja tempat kerja (Bryson et al, 2018). Peneliti telah membuat konsep bahwa praktik manajemen sumber daya (MSDM) berdampak pada kinerja karyawan melalui jalur kognitif dimana sebuah karyawan memanfaatkan lebih banyak keterampilan dan kemampuan, dan jalur motivasi, di dalamnya praktek MSDM meningkatkan motivasi karyawan untuk sukses di tempat kerja (Bates, Cox, Robertson-Smith, \& Garrett, 2009).

Ada beberapa alasan mengapa sekolah dapat memperoleh manfaat dari adanya manajemen sumber daya (MSDM). Pertama, karena guru memainkan peran utama dalam prestasi siswa (Rivkin et al., 2005), keberhasilan sekolah dalam memenuhi harapan yang terus meningkat terkait prestasi siswa terutama bergantung pada kompetensi dan upaya guru mereka. Manajemen sumber daya (MSDM) dapat dilihat sebagai sarana untuk memotivasi guru untuk berkontribusi pada tujuan sekolah mereka. Kedua, ada aliran wawasan psikologis baru yang berkelanjutan tentang pedagogi dan pembelajaran yang ditanamkan di sekolah (OECD, 2009, 2014). Guru adalah orang yang harus bersedia untuk terus memprofesionalkan diri mereka sendiri dengan memasukkan wawasan baru ini ke dalam praktik sehari-hari mereka, dan MSDM dapat dilihat sebagai cara bagi sekolah untuk menawarkan kesempatan kepada guru mereka untuk profesionalisasi berkelanjutan. Akhirnya, di seluruh dunia sekolah mengalami kesulitan untuk menemukan cukup guru yang berkualifikasi tinggi (OECD, 2014), dan bahkan jika sekolah dapat menemukannya, terlalu banyak guru muda berhenti karena fakta bahwa lingkungan kerja tidak memenuhi harapan mereka (OECD, 2009). Sistem MSDM dapat membantu sekolah dalam menarik dan mempertahankan guru yang cukup kompeten dan termotivasi (Loeb et al., 2012). Marwansyah (2010:4) Manajemen Sumber Daya Manusia adalah pendayagunaan sumber daya manusia di dalam organisasi, yang dilakukan melalui fungsi-fungsi perencanaan sumber daya manusia, rekrutmen dan seleksi, pengembangan sumber daya manusia, perencanaan dan pengembangan karir, pemberian kompensasi dan kesejahteraan, keselamatan dan kesehatan kerja, dan hubungan industrial. Dalam Penelitian ini faktor pembentuk praktek MSDM mengadaptasi dari lee et al 2019, yaitu : (1) Jaminan Pekerjaan, (2) Pelatihan dan Pengembangan, (3) Pengukuran Kinerja, (4) Partisipasi dalam Pengambilan Keputusan, (5) Kesetaraan Status, (6) Reward. Kata kinerja atau prestasi berasal dari kata "Performance" yang berarti: prestasi, pertunjukan, pelaksanaan tugas. Prawirosentono (2008) mendefinisikan kinerja yaitu "Performance adalah hasil kerja yang dapat dicapai oleh seseorang atau sekelompok orang dalam suatu organisasi sesuai dengan wewenang dan tanggungjawab masing-masing, dalam rangka upaya mencapai tujuan organisasi bersangkutan secara legal, tidak melanggar hukum dan sesuai dengan moral maupun etika. Dalam Penelitian ini faktor pembentuk kinerja guru olahraga diadaptasi dari Kopmans et al 2014 yaitu : (1) kinerja tugas, (2) kinerja kontekstual, (3) kinerja adaptif, (4) perilaku kerja kontra-produktif. Berdasarkan pemaparan tersebut tujuan penelitian ini adalah menjelaskan hubungan praktek MSDM terhadap kinerja guru olah raga.

\section{Metodologi Penelitian}

Penelitian ini menggunakan pendekatan positivisme dengan metode kuantitatif. Data yang digunakan dan dianalisis dalam penelitian ini adalah data kualitatif yaitu berupa pendapat responden yang menyatakan setuju atau tidak setuju tentang sesuatu yang kemudian dikuantitatifkan. jenis penelitian yang digunakan dalam penelitian ini adalah jenis penelitian explanatory. Penelitian explanatory merupakan suatu penelitian yang menjelaskan 
hubungan kausal antara variabel penelitian dan pengujian hipotesis (Cooper and Schindler, 2014).

Penelitian ini dilakukan untuk mengetahui gambaran tentang adanya pengaruh Praktek MSDM terhadap kinerja Guru. Data penelitian ini diperoleh dari pengisian kuesioner oleh responden yang berisi 12 pertanyaan dengan 5 skala likert yang dilakukan secara online. Penyebaran kuesioner dilakukan antara bulan Agustus sampai Oktober 2020. Teknik pengambilan sampel yang digunakan adalah probabilty sampling yang terdiri dari 102 guru olahraga di kota Malang dan sekitarnya. Jenis kelamin dari responden adalah 89 guru olahraga pria dan 13 guru olahraga wanita.

Analisis data dilakukan menggunakan SEM-PLS dengan software WARP PLS 7. Validitas pada penelitian ini diukur dengan menggunakan kriteria output combined loadings dan cross loadings, jika nilai loading factor lebih dari 0.40 dan nilai p signifikan kurang dari 0.05 $(<0.05)$ maka indikator atau item tersebut dinyatakan valid. Penilaian reliabilitas didasarkan pada composite reliability dan cronbach's alpha. Keduanya harus bernilai diatas 0.70 sebagai syarat reliabilitas.

\section{Hasil dan Pembahasan}

Tabel 1. Hasil Uji Validitas Instrumen Penelitian

\begin{tabular}{clccc}
\hline & & \multicolumn{2}{c}{ Uji Validitas } & \\
Variabel & \multicolumn{1}{c}{ Item } & $\begin{array}{c}\text { Outer } \\
\text { Loadin }\end{array}$ & $\begin{array}{c}\text { P- } \\
\text { Value }\end{array}$ & Keteranga \\
& & $\mathrm{g}$ & & $\mathrm{n}$ \\
& & 0.089 & $<0,001$ & Valid \\
& X 1 Jaminan Pekerjaan & 0.083 & $<0,001$ & Valid \\
& X 2 Pelatihan dan Pengembangan & 0.084 & $<0.001$ & Valid \\
& X 3 Pengukuran Kinerja & 0.083 & $<0,001$ & Valid \\
Praktek & X 4 Partisipasi dalam Pengambilan & & & \\
MSDM & $\quad$ Keputusan & 0.081 & $<0.001$ & Valid \\
& X 5 Kesetaraan Status & 0.081 & $<0,001$ & Valid \\
& X 6 Reward & 0.081 & $<0,001$ & Valid \\
& Y 1 kinerja tugas & 0.080 & $<0,001$ & Valid \\
Kinerja & Y 2 kinerja kontekstual & 0.086 & $<0,001$ & Valid \\
Guru & Y 3 kinerja adaptif & 0.082 & $<0,001$ & Valid \\
\hline
\end{tabular}

Sumber : Data diolah, 2021 
Berdasarkan tabel 1 dapat dilihat bahwa outer loading dan p lebih kecil dari $0.05(<0.05)$ yang berarti tiap-tiap indikator variabel adalah valid, sehingga dapat disimpulkan bahwa indikator-indikator tersebut dapat digunakan untuk mengukur variabel penelitian.

Tabel 2. Hasil Uji Reliabelitas Instrumen Penelitian

\begin{tabular}{llll}
\hline & \multicolumn{2}{c}{ Uji Reliabilitas } & \\
\multicolumn{1}{c}{ Variabel } & Cronbach's & Composite & Keterangan \\
& Alpha & Reliable & \\
\hline Praktek MSDM & 0.977 & 0.981 & Reliabel \\
Kinerja Guru & 0.913 & 0.933 & Reliabel \\
Olahraga & & & \\
\hline
\end{tabular}

Sumber : Data diolah, 2021

Tabel 2 menunjukkan jika composite reliability dari 3 variabel seluruhnya di atas 0.70 dengan rincian sebagai berikut: praktek MSDM sebesar 0.981, kinerja guru olahraga sebesar 0.933. Nilai cronbach's alpha dari 3 variabel juga menunjukkan nilai di atas 0.70 dengan rincian sebagai berikut: praktek MSDM sebeasr 0.977 dan kinerja guru olahraga sebesar 0.913.

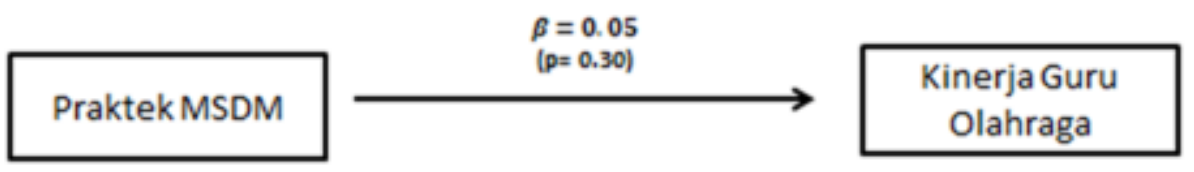

Gambar 1. Model SEM-PLS Pengujian Pengaruh Langsung

Hasil penelitian menunjukkan jika hubungan praktek MSDM dan kinerja guru olahraga berpengaruh negatif $(0.05)$ dengan signifikansi nilai p sebesar $0.30(<0.005)$. Nilai tersebut menandakan jika kinerja guru olahraga tidak dipengaruhi oleh praktek MSDM, hasil tersebut bertolak belakang dengan penelitian yang dilakukan oleh (Waseem et al 2016) yang menunjukkan jika praktek MSDM berpengaruh terhadap kinerja guru di Pakistan. Hasil dari penelitian ini juga bertolak belakang dengan (Jyoti et al, 2020) yang menemukan jika praktek MSDM berpengaruh positif kinerja guru di India.

\section{Kesimpulan}

Berdasarkan hasil penelitian tentang pengaruh praktek MSDM terhadap KInerja guru olahraga selama pandemi covid-19 dapat ditarik kesimpulan bahwa praktek MSDM tidak mempengaruhi kinerja guru olahraga. Dari penjelasan yang telah dipaparkan maka dapat diketahui jika selama pandemi covid-19, praktek MSDM yang yang diterapkan oleh sekolah tidak berdampak pada kinerja guru olahraga. Hal tersebut berarti apabila praktek MSDM yang diterapkan oleh sekolah semakin tinggi maka kinerja guru olahraga di sekolah tersebut belum tentu menjadi tinggi pula. Pandemi Covid-19 yang terjadi saat ini, membuat banyak perubahan dalam sistem manajemen di sekolah terutama di lingkung MSDM. Pandemi juga membuat tuntutan perubahan sistem manajemen harus dilakukan dengan cepat. Perubahan tersebut tentu harus dibarengi dengan proses adaptasi yang cepat dari sumber daya manusia yang ada di sekolah termasuk guru olahraga. Tidak adanya pengaruh praktek MSDM 
terhadap kinerja guru olahraga dimungkinkan karena adanya proses adaptasi dari perubahan tersebut. Penelitian ini dibatasi pada variabel praktek MSDM dan kinerja guru olahraga, tidak menutup kemungkinan jika ada variabel lain yang mempengaruhi kinerja guru olahraga.

\section{Daftar Pustaka}

Abdullah, N. H., Wahab, E., \& Shamsuddin, A. (2019). Creative self-efficacy, innovative work behaviour and job performance among selected manufacturing employees. Journal of Social Sciences Research, 5(2), 291-297. https:// doi.org/10.32861/jssr.52.291.297

Akpakwu, S.O. (2012). Educational management: Theory and Practice. Makurdi: Destiny Ventures

Bates, P., Cox, A., Robertson-Smith, G. \& Garrett, R. (2009), High Performance Working: Developing a Survey Tool, London, UK.

Bryson, A., Stokes, L., \& Wilkinson, D. (2020). Can MSDM improve schools' performance? Labour: Review of Labour Economics and Industrial Relations.

Cooper, Donald R \& Schindler, Pamela S. (2014). Business Research Method, $12^{\text {th }}$ edition. McGraw Hill, New York

Koopmans, L., Bernaards, C., Hildebrandt, V., Van Buuren, S., Van Der Beek, A. J., \& de Vet, H. C. w. (2012). Development of an individual work performance questionnaire. International Journal of Productivity and Performance Management, 62(1), 6-28. https://doi.org/10.1108/17410401311285273

Lee, J., Kim, S., Lee, J., \& Moon, S. (2019). Enhancing employee creativity for a sustainable competitive advantage through perceived human resource management practices and $\begin{array}{llll}\text { trust in management. Sustainability } & \text { (Switzerland), }\end{array}$ https://doi.org/10.3390/su11082305

Loeb S, Kalogrides D and Beteille T. (2012). Effective schools: Teacher hiring, assignment, development, and retention. Education 7(3): 269-304.

Marwansyah. 2010. Manajemen sumber daya manusia. Alfabeta:Bandung.

OECD. (2009). Creating Effective Teaching and Learning Environments: First Results from TALIS. Paris: Organization for Economic Cooperation and Development

OECD. (2014). TALIS 2013 Results. An International Perspective on Teaching and Learning. Paris: Organization for Economic Cooperation and Development

Rivkin, S.G., Hanushek, E.A. and Kain, J.F. (2005). Teachers, schools, and academic achievement. Econometrica 73(2): 417-458.

Runhaar P and Runhaar H. (2012). HR policies and practices in vocational education and training institutions: understanding the implementation gap through the lens of discourses. Human Resources Development International, 15 (5), 609-625.

Shalley, C. E. \& Perry-Smith, J. E. (2001), “Effects of Social-Psychological Factors on Creative Performance: The Role of Informational and Controlling Expected Evaluation and Modeling Experience", Organizational Behaviors and Human Decision Processes, 84(1): 1-22. 
Tang, G., Wei, L.Q., Snape, E. and Ying, C.N. (2015). How effective human resource management promotes corporate entrepreneurship: evidence from China. International Journal of Human Resource Management. Vol. 26 No. 12, pp. 1586-1601.

Waseem, S.N., Farooghi, R., Afshan, S., (2016). Impact of Human Resource Management Practices on Teachers' Performance: A Mediating Role of Monitoring Practices.

Woodman, R.W. and Schoenfeldt, L.F. (1990). An interactionist model of creative behavior. Journal of Creative Behavior, Vol. 24 No. 1, pp. 279-290.

Zacharatos, A., Barling, J. and Iverson, R. (2005). High-performance work systems and occupational safety. Journal of Applied Psychology. Vol. 90 No. 1, pp. 77-93 